\title{
POPULATION STUDIES OF INV(9) CHROMOSOMES IN 4,300 JAPANESE: INCIDENCE, SEX DIFFERENCE AND CLINICAL SIGNIFICANCE
}

\author{
Kiyomi Yamada \\ Division of Genetics, Clinical Research Institute, National Medical Center, \\ Toyama, Shinjuku-ku, Tokyo 162, Japan
}

\begin{abstract}
Summary Population incidence of a chromosome 9 with an inversion of $\mathrm{qh}$, inv(9), was surveyed using C-banding in a total of 4,367 Japanese which consisted of five patient groups and a normal control group. The inv(9) incidence was $1.65 \%$ in the normal control group $(n=1,513)$ and $1.52 \%$ in the Down syndrome patient group $(\mathrm{n}=1,246)$. The incidence of female carriers was 1.7 times higher than that of male carriers in the above two groups. The sex difference was significant $(\mathrm{p}<0.05)$. Moreover, the incidence in the $47, \mathrm{XXY}$ male group $(\mathrm{n}=277)$ was slightly higher than female carrier incidences. The excess of carriers about 2 times was observed in the habitual abortion couple group $(n=694)$ and the spontaneous abortus group $(n=181)$, both having normal karyotypes. The present data probably indicate the existence of a genetic effect of inv(9) on human reproductive performance, while they could not explain the sex difference found in inv(9) carriers. Our speculation for the sex difference has been presented.
\end{abstract}

Key Words inv(9) chromosome, population incidence, sex difference, habitual abortion couples, aborted fetuses

\section{INTRODUCTION}

The inv(9) chromosome is generally considered a normal variant without any effect on the phenotype of individuals carrying this anomaly, merely by the reason that this chromosome is a morphologically variant chromosome observed most frequently among normal healthy individuals. Therefore, inv(9) variants seem to be suitable material for analysis on the genetic effect of polymorphic chromosomes in man. We have previously reported an association between $Y$ chromosome length polymorphism and stature (Yamada et al., 1981; Yamada, 1985).

Received August 24, 1992; Accepted September 25, 1992. 
Incidence of inv(9) reported in the literature varies, depending on the population studied and the staining techniques used. Drawing our interest was the point that some investigators have suggested an association of inv(9) and reproductive failure (de la Chapelle et al., 1974; Boue et al., 1975; Tho et al., 1982). However, other investigators did not find an excess of inv(9) carriers and have argued that inv(9) variants do not play an important role in etiology of recurrent fetal loss (Ward et al., 1980; Fryns et al., 1984). The past data on inv(9) were based on relatively small samples of a few hundred patients with different controls and different staining techniques, so that the conclusions are uncertain due to variations in the methodological aspects. Therefore, it is still unclear whether the inv(9) variant is preferentially associated with patients with a particular abnormality, or what is its biological meaning or effect in man. To obtain informative evidence for the above questions, large scale surveys of populations using reliable methods on the inv(9) incidence in normal and patient populations are needed.

We have been doing a population survey on the inv(9) incidence during the last decade using a reliable $\mathrm{C}$-banding method. To investigate the possible biological meaning or genetic load, we compared the inv(9) incidence in various patient populations with that of a normal healthy control group. Our present study has revealed the possible existence of differences between subjects with and without an inverted chromosome 9 from genetic and biological aspects.

\section{MATERIALS AND METHODS}

The following six populations consisting of five patient groups and a normal control group were subjected to an analysis on the incidence of inv(9): normal healthy volunteers (NR), 21-trisomy Down syndrome patients (DW), 47-XXYKlinefelter syndrome patients (KF), azoo-or-oligospermia patients (AZ), couples with a history of more than two spontaneous first trimester abortions (HA), and spontaneously aborted fetuses (SA) with a normal (SA ${ }^{\mathrm{NR}}$ ) or abnormal karyotypes $\left(S^{A B N}\right)$. Couples (HA) and aborted fetuses (SA) were unrelated populations, i.e., materials of the former were collected from hospitals in the Tokyo metropolitan area and of the latter were sent by mail from a national hospital in Nagoya City. The ages of individuals ranged from 1 to 5 years in the DW group, and from 20 to 50 years in the others (except SA).

Chromosome slides were freshly made from the cytogenetic material stocked in freezers for a few years after chromosome analysis, which was obtained by the blood culture method (NR, DW, KF, AZ, HA) or by the short-term culture of chorionic villi (SA). Heterochromatic C-bands on chromosomes were produced by the DA/DAPI method of Schweizer et al. (1978) with modification. Chromosome slides were stained with distamycin A (DA), $0.1 \mathrm{mg} / \mathrm{ml}$ for $12 \mathrm{~min}$, and rinsed briefly in $\mathrm{pH} 7.0$ Macllvaine buffer. Then, the slides were again stained with diamidino-phenyl-indole (DAPI), $0.5 \mu \mathrm{g} / \mathrm{ml}$ for $15 \mathrm{~min}$, and mounted with glycerol- 
buffer $(1: 1)$. The slides were left in a cold dark room for at least $6 \mathrm{hr}$. Analysis of the C-band position was performed on chromosome pairs 1, 9, and 16; at least 5 cells per individual were examined under a fluorescence microscope with a vertical epi-illuminator (Olympus, Inc.). A pericentric inversion of C-band heterochromatin $(9 \mathrm{qh})$ was defined in this study as an inv(9) chromosome.

\section{RESULTS}

The incidence of the occurrence of inv(9) carriers in six populations studied is shown in Table 1. All the inv(9) found were total inversion and the absolute majority of them seerned to be of a single type inv(9)(p11q13) from alteration of the arm ratio. A partial inv( 9 ) and any instance of the C-band inversion in chromosomes 1 and 16 were not observed in the subjects of the present study.

\section{Population incidence and sex difference}

Out of 1,513 individuals examined in the NR group, 25 individuals $(1.65 \%)$ had inv(9). Furthermore, in the DW group of 1,246 patients examined, the incidence of inv(9) was $1.52 \%$, close to but slightly lower than that of the NR group. Homozygotes (inv/inv) for the inversion were found in only 2 (female NR and male DW) of all the individuals examined in the present study. In the NR group, the incidence in females was found to be 1.7 times higher than that in males $(2.07 \%$ vs. $1.22 \%$ ). Very similar finding was obtained in the DW group $(2.00 \%$ vs. 1.15 $\%$ ). The sex difference in the frequency of inv(9) carriers was statistically analyzed using combined data of NR and DW groups, by counting the number of individuals examined from one carrier until the next one was found. The mean number of individuals in intervals between carriers was $42.6($ S.D. $=32.2 ; n=25)$ in the female group, and 88.3 (S.D. $=72.7 ; \mathrm{n}=15$ ) in the male group. The difference between the two means was statistically significant $(\mathrm{t}=2.30 ; \mathrm{p}<0.05)$. Furthermore, an

Table 1. Incidences of inv(9) carriers in a normal and 5 patient populations.

\begin{tabular}{lccc}
\hline Populations & $\begin{array}{c}\text { No. examined; } \\
\text { total }(\mathrm{F} / \mathrm{M})\end{array}$ & $\begin{array}{c}\text { Carriers found; } \\
\text { total }(\mathrm{F} / \mathrm{M})\end{array}$ & $\begin{array}{c}\text { Incidence, \%; } \\
\text { total }(\mathrm{F} / \mathrm{M})\end{array}$ \\
\hline NR & $1,513(773 / 740)$ & $25(16 / 9)$ & $1.65(2.07 / 1.22)$ \\
$\mathrm{DW}$ & $1,246(548 / 698)$ & $19(11 / 8)$ & $1.52(2.00 / 1.15)$ \\
KF & 277 & 7 & $2.53(-/ 2.53)$ \\
$\mathrm{AZ}$ & 230 & 3 & $1.30(-/ 1.30)$ \\
HA & $752(376 / 376)$ & $24(9 / 15)$ & $3.19(2.39 / 3.99)$ \\
SA & $181(103 / 78)$ & $6(4 / 2)$ & $3.31(3.88 / 2.56)$ \\
SA & 168 & 1 & 0.60 \\
Total & 4,367 & 85 & 1.95 \\
\hline
\end{tabular}

inv(9), total inversion. 
interesting observation was the finding in the KF group, i.e., in studies of 277 men with a $47, \mathrm{XXY}$ karyotype the incidence of inv(9) was $2.53 \%$, slightly higher than that of females in the NR or DW group. On the other hand, in the AZ patients who were considered as controls for the KF patients, the incidence was $1.30 \%$, being within the range of males in the NR and DW groups.

\section{Preferential association with particular patient groups}

In the HA group, chromosome analysis was performed on 376 couples with repeated early spontaneous abortions; $29(7.7 \%)$ couples had chromosome abnormalities mostly due to reciprocal translocations of the balanced type without any case showing an inv(9). By C-banding, 23 couples with normal karyotypes were found to have inv(9) $(9$ wives and 15 husbands, including a couple of heterozygous carriers). In the $S A^{N R}$ group, the inv(9) incidence was very close to that of the HA group and about 2 times higher than that of the control group; $\mathrm{C}$-banding revealed 6 carriers out of 181 aborted fetuses examined in the SA ${ }^{\mathrm{NR}}$ group. The 168 cases of the $\mathrm{SA}^{\mathrm{ABN}}$ group were 34 cases of $\mathrm{X}$-monosomy, 82 cases of trisomy including 3 cases of trisomy 9,41 cases of polyploidy, and 11 cases of structural chromosome abnormalities of mostly unbalanced types. However, the inv(9) was found only in one of the X-monosomy cases, showing a lower incidence than that of the SANR or NR group, though the number of individuals examined was small.

\section{DISCUSSION}

In Table 2 is summarized the population incidence of inv(9) previously reported by other investigators. It was noteworthy that the prevalence of inv(9) has been reported especially in patients with mental retardation, reproductive failure, and leukemias.

The reported incidences varied among investigators. From our experience, differences in the banding methods used seemed to be a large factor. At the beginning of our survey, we used the BSG method (Sumner, 1972) for C-banding. However, depending on the age of the slide and the length of treatment in alkali solution, the dark-stained heterochromatic C-block varied in size and sometimes it was difficult to decide whether it was a total or partial inversion. Further, we experienced a case in which a partial inversion diagnosed by the BSG method, was shown not to be inversion by the DA/DAPI method. The same finding was already pointed out by Buys et al. (1981). According to the report of Mattei et al. (1981), the heterochromatin of chromosome 9 is composed of two chemically different subunits; centromeric heterochromatin and secondary constriction heterochromatin. Most popular C-banding methods, using alkali treatment and Giemsa stain, usually reveal both types of heterochromatin. This is probably the reason why the incidence of partial inversions varied so widely among investigators. However, a true partial inversion seems to be very rare (Gosden et al., 1981). 
Table 2. Population incidences of inv(9) chromosomes reported.

\begin{tabular}{|c|c|c|c|c|}
\hline Population (Country) & $\begin{array}{l}\text { No. Carrier } \\
\text { (Incider }\end{array}$ & $\begin{array}{l}\text { Is/Total } \\
\text { ance, \&) }\end{array}$ & $\begin{array}{l}\text { Banding } \\
\text { method }\end{array}$ & Author, Year \\
\hline $\begin{array}{l}\text { 1) patients referred to the genetic } \\
\text { clinic (England) }\end{array}$ & $3 / 200$ & $(1.508)$ & QFQ & $\begin{array}{l}\text { Mutton and } \\
\text { Dakex. } 1973\end{array}$ \\
\hline $\begin{array}{l}\text { 1) Patients referred to the genetic } \\
\text { clinic (England) }\end{array}$ & $8 / 282$ & $(2.848)$ & QFQ, GTG & $\begin{array}{l}\text { Madan and } \\
\text { Bobrow, } 1974\end{array}$ \\
\hline $\begin{array}{l}\text { 1) Patients referred to the genetlc } \\
\text { clinic (Finland) }\end{array}$ & $6 / 631$ & $(0.958)$ & GTG-CNG & $\begin{array}{l}\text { De la Chapelle } \\
\text { et } a l,, 1974\end{array}$ \\
\hline 1) Newborn bables (USA) & $4 / 354$ & $(1.138)$ & CBG & $\begin{array}{l}\text { Mu1ler } \in t a l \text {, } \\
1975\end{array}$ \\
\hline $\begin{array}{l}\text { 1) Newborn bables }(U . K) \\
\text { 2) } 14 \text { year-old normal children (U.K.) } \\
\text { 3) Old persons, aged > } 65 \text { years (U.K.) }\end{array}$ & $\begin{array}{l}7 / 467 \\
2 / 101 \\
0 / 210\end{array}$ & $\begin{array}{l}(1.508) \\
(2.008) \\
(0 / 008)\end{array}$ & $\begin{array}{l}\text { CBG } \\
\text { CBG } \\
\text { CBG }\end{array}$ & $\begin{array}{l}\text { Buckton et al., } \\
1976\end{array}$ \\
\hline $\begin{array}{l}\text { 1) Normal and mentally retarded } \\
\text { children, White (USA) } \\
\text { 2) Normal and mentally retarded } \\
\text { chidren, Black (USA) }\end{array}$ & $\begin{array}{l}4 / 2,541 \\
15 / 1,457\end{array}$ & $\begin{array}{l}(0.168) \\
(1.038)\end{array}$ & $\begin{array}{l}\text { CBG } \\
\text { CBG }\end{array}$ & $\begin{array}{l}\text { Lubs et al. } \\
1977\end{array}$ \\
\hline $\begin{array}{l}\text { 1) Mentally retarded patients (USA) } \\
\text { 2) Phenotypically normal adults (USA) }\end{array}$ & $5 / 200$ & $\begin{array}{l}(2.508) \\
(1.008)\end{array}$ & CBG & $\begin{array}{l}\text { Tharapel and } \\
\text { Summit, } 1979\end{array}$ \\
\hline 1) Mentally retarded patients (USA) & $6 / 403$ & $(1.498)$ & CBG & $\begin{array}{l}\text { Matsuura } \\
\text { et al., } 1978\end{array}$ \\
\hline $\begin{array}{l}\text { 1) Patients referxed to the genetic } \\
\text { clinic (Greece) }\end{array}$ & $25 / 600$ & $(4.178)$ & G-11 & $\begin{array}{l}\text { Metaxotou } \\
\text { et al., } 1978\end{array}$ \\
\hline $\begin{array}{l}\text { 1) Patients with hematologio dis - } \\
\text { orders (Israel) } \\
\text { 2) Newborn babies (Israel) }\end{array}$ & $\begin{array}{l}8 / 120 \\
6 / 800\end{array}$ & $\begin{array}{l}(6.678) \\
(0.758)\end{array}$ & $\begin{array}{l}\text { CBG } \\
\text { CBG }\end{array}$ & $\begin{array}{l}\text { Shabtal and } \\
\text { Halbrecht, } 1979\end{array}$ \\
\hline $\begin{array}{l}\text { 1) Couples with repeated abortions } \\
\text { (USA) } \\
\text { 2) Other patients (USA) }\end{array}$ & $\begin{array}{l}2 / 200 \\
2 / 184\end{array}$ & $\begin{array}{l}(1.008) \\
(1.098)\end{array}$ & $\begin{array}{l}\text { GTG } \\
\text { GTG }\end{array}$ & $\begin{array}{l}\text { Ward et al. } \\
1980\end{array}$ \\
\hline $\begin{array}{l}\text { 1) Couples with repeated abortions } \\
\text { (Italy) }\end{array}$ & $4 / 290$ & $(1.388)$ & CBG & $\begin{array}{l}\text { Bortotto } \\
\text { et al., } 1980\end{array}$ \\
\hline $\begin{array}{l}\text { 1) Patients referred to the genetic } \\
\text { clinic (France) }\end{array}$ & $65 / 6,845$ & $(0.948)$ & $R-G 11$ & $\begin{array}{l}\text { Mattel et al., } \\
1981\end{array}$ \\
\hline $\begin{array}{l}\text { 1) Couples with repeated abortions } \\
\text { (USA) } \\
\text { 2) Other patients (USA) }\end{array}$ & $\begin{array}{l}6 / 220 \\
21 / 1,589\end{array}$ & $\begin{array}{l}(2.738) \\
(1.328)\end{array}$ & $\begin{array}{l}\mathrm{DA} / \mathrm{DAPI} \\
\mathrm{DA} / \mathrm{DAPI}\end{array}$ & $\begin{array}{l}\text { Tho et al. } \\
1982\end{array}$ \\
\hline
\end{tabular}

inv(9), total inversion; QFQ, Q-band/Fluorescence/Quinacrine; GTG, G-band/Trypsin/Giemsa; CNG or CBG, C-band/sodium or barium hydroxide/Giemsa; G-11, C-band/pH 11/Giemsa; R, R-band/Giemsa; DA/DAPI, C-band/Distamycin A and DAPI.

Mattei et al. (1981) reported two methods which can stain exclusively the secondary constriction heterochromatin without staining the centromeric heterochromatin; the G11.6 method (Gagne and Laberge, 1972), and the DA/DAPI method. We think that the DA/DAPI method used in this study is simple, reliable and one of the best C-banding methods for detection of inv(9).

A sex difference in inv(9) carriers, hitherto unreported, was revealed by the present study. Segregations between chromosome 9 homologs and between sex 
chromosomes should occur independently at the meiotic division in the testes, so that the X-sperm and the Y-sperm, both having an inv(9), are theoretically produced in an equal frequency. The present study revealed a decreased number of male inv(9) carriers among normal controls. Natural selection according to the sex must have occurred somewhere. It can be inferred from the present study that sperm having an inv(9) possess an equal ability to fertilize oocytes as do sperm with a normal chromosome 9: inv(9) carriers of the HA group consisted of 9 wives and 15 husbands, in contrast to 22 wives and 5 husbands of reciprocal translocation carriers. The relative scarcity of male translocation carriers involved in the HA group is generally explained by sperm elimination before or sperm selection at fertilization (Chandley et al., 1975). In contrast to male translocation carriers, in the case of inv(9) carriers sperm selection would not occur at fertilization. The selective loss of male fetuses with inv(9) might occur during early fetal development. However, the abortus material of the present study did not prove this assumption, though the overall incidence of inv(9) carriers was higher in the SA ${ }^{\mathrm{NR}}$ group. Our further study by extensive accumulation of abortus cases will give a clue for the problem.

In the present study, the risk of inv(9) carriers for abortions was roughly estimated from comparison of carrier incidences. The result showed that the carrier incidence of the HA group was 3.5 times higher in husbands and 1.3 times higher in wives than the incidence in the normal control group, when taking into consideration of the sex difference (Table 3). In wives of male inv(9) carriers, the poor reproductive outcome due to long-standing interfility and early abortions (Boue et al., 1975; Tho et al., 1982) and reduced numbers of offspring (de la Chapelle et al., 1974) have been reported. Therefore, it seems likely that males, rather than females, are slightly more susceptible to genetic impairment related to the inv(9) in terms of reproduction failure. In addition to reciprocal translocations, we would like to emphasize the notion that an inv(9) must be considered as a chromosomal variant related to repeated early abortions.

The following interesting findings are reported in the literature: According to Hansmann (1976), inv(9) were classified into three common types: type I, inv(9) (p11q13); type II, inv(9)(p11q12); and type III, inv(9)(p13q13). Further, he dem-

Table 3. Estimated risk of inv(9) carriers for abortions.

\begin{tabular}{lr} 
Population & Incidence, \% \\
\hline NR & Female $(n=773): 2.07$ \\
HA & Male $(n=740): 1.22$ \\
(excluding couples with chromosome abnormalities) & Female $(n=347): 2.59$ \\
Estimated risk for abortions: Females: 1.3 times higher than non-carriers \\
\end{tabular}


onstrated that the breakpoints were very specific for inv(9) and not hot 'spots' in translocations observed in congenitally abnormal patients, Bloom syndrome patients, and lymphocytes after the experimental X-ray exposure. Kaiser (1984) has summarized the following interesting observations from the analysis of 72 reported cases. i) Breakpoint specificity and ciustering; of the 72 reported cases 56 were of type I, 4 of type II, 3 of type III, and 5 of uncommon types (one case each). ii) Occurrence and recombination; all cases of common types were of familial occurrence without recombination of chromosome 9 , contrasting to 1 case of de novo mutation and 3 cases of recombinants out of 5 cases with uncommon breakpoints. iii) Segregation in family members; the segregation pattern was not different from the expected distribution of $1: 1$. iv) Spermatogenesis; apparently normal histology of testes and normal pairing with the exception of the inverted segment. reported in 3 carrier males. v) Predisposition to nondisjunction; out of 10 patients with mosaic trisomy 9 reported, 5 were found to have inv(9) which was double in trisomic cells and of maternal origin in all the cases (Willatt et al., 1991).

The following is our speculative consideration on the genetic effect of inv(9): We suppose that an inv(9) chromosome seems to be an unfavorable character to human reproduction. This adverse effect may be critical not at fertilization but mostly in early fetal development by sjightly reducing viability of carrier fetuses. This thought is substantiated by the present results; $i)$ a higher population incidence in the $S A^{N R}$ group, ii) the scarcity of $S^{A B N}$ fetuses with an inv(9) probably due to lower viability, and iii) a higher risk of reproductive failure in living inv(9) carriers. Regarding the preponderance of female living inv(9) carriers, we would like to speculate on one possibility: The weight of the genetic load must differ slightiy between males and females, probabiy by the difference of the gene dosage of X-chromosomal genes. Consequently, normal females (and inversion carrier females) with disomic X-chromosomes are genetically prone to have more biological viability than normal males (and inversion carrier males) with hemizygous $\mathrm{X}$-linked genes. The data of the $\mathrm{KF}$ group in the present study strongly support our hypothesis. Also, longer average life-span of females which is preceding that of males more than 4 years in most advanced nations (1989 Demographic Yearbook, 1991) may give a support to our hypothesis.

The present study excludes the association of inv(9) and 21-trisomy (Down syndrome) suggested previously by some investigators (Boue et al., 1975; Hernandez et al., 1979; Wang and Hamerton, 1979; Serra et al., 1980). Cytogenetic mechanisms related to the genetic effect of inv(9) are still unknown even in the light of reported evidence. The inverted segment size of an inv(9)(pl1q13) is estimated to be $20 \%$ of the length of chromosome 9 (Kaiser, 1984). The high prevalence of inv(9) and of its familial occurrence probably indicates that the genetic effect of inv(9) in man is essentially tolerable through the alteration of generations. Accordingly, an inv(9) must be interpreted as a normal variant, but, as having 
disease susceptibility. In future, molecular studies in the breakage cluster region of p 11 and q13 of chromosome 9 will be needed to clarify mechanisms for the genetic effect of an inv(9). The past data reported in the literature on the size variation and pericentric inversion of C-band heterochromatin are mostly unreliable from methodological aspects, so that they must be revised before discussing their clinical significance.

Acknowledgments The author thanks to the following persons for supplying the material and without whose help this study could not have been performed: Drs. N. Kuroki and R. Totani, Nagoya National Hospital, Nagoya; Dr. K. Isurugi, Osaka Medical College, Osaka; Drs. T. Wagatsuma, S. Minoura and T. Hasegawa, our hospital. The author is also grateful to Dr. A. A. Sandberg, The Cancer Center, Arizona, for reading and correcting the manuscript, and to Mrs. N. Arita for technical assistance.

\section{REFERENCES}

Bortotto L, Baccichetti C, Lenzini E, Tenconi R, Delendi N, Caufin D (1980): Cytogenetic survey of couples with habitual abortion and other reproductive wastage. Clin Genet 17: 56-57

Boue J, Taillemite JL, Hazael-Massieux P, Leonard C, Boue A (1975): Association of pericentric inversion of chromosome 9 and reproductive failure in ten unrelated families. Humangenetik 30: $217-224$

Buckton KE, O'Riordan ML, Jacobs PA, Robinson JA, Hill R, Evans HJ (1976): C- and Q-band polymorphisms in the chromosomes of three human populations. Ann Hum Genet 40: 99112

Buys CHCM, Gouw WL, Blenkers JAM, van Dalen CH (1981): Heterogeneity of human chromosome 9 constitutive heterochromatin as revealed by sequential Distamycin A/DAPI staining and C-banding. Hum Genet 57: 28-30

Chandley AC, Edmond P, Christle S, Gowans I, Fletcher J, Frackiewicz A, Newton M (1975): Cytogenetics and infertility in man. I. Karyotype and seminal analysis. Ann Hum Genet 39: 231-254

de la Chapelle A, Schroder J, Stenstrand K, Fellmann J, Herva R, Saarni M, Anttolainen I, Tallila I, Tervila L, Husa L, Tallquist G, Robson EB, Cook PJL, Sanger R (1974): Pericentric inversions of human chromosomes 9 and 10. Am J Hum Genet 26: 746-766

Demographic Yearbook-1989. Department of International Economics and Social Affairs, Statistical Office, United Nations, 1991

Fryns JP, Kleczkowska A, Kubien E, Petit P, Van den Berghe H (1984): Cytogenetic survey in couples with recurrent fetal wastage. Hum Genet 65: 336-354

Gagne R, Laberge C (1972): Specific cytologic recognition of the heterochromatic segment of number 9 chromosome in man. Exp Cell Res 73: 239-242

Gosden JR, Spowart G, Lawrie SS (1981): Satellite DNA and cytological staining patterns in heterochromatic inversions of human chromosome 9. Hum Genet 58: 276-278

Hansmann I (1976): Structural variability of human chromosome 9 in relation to its evolution. Hum Genet 31: 247-262

Hernandez A, Rivera H, Jimenez-Sainz M, Cantu JM (1979): Familial trisomy 21 and pericentric inversion (9)(p11q13). Ann Genet 22: 40-42

Kaiser P (1984): Pericentric inversions. Problems and significance for clinical genetics. Hum Genet 68: $1-47$

Lubs HA, Patil SA, Kimberling WJ, Brown J, Cohen M, Gerald P, Hecht F (1977): Q and C banding polymorphisms in 7- and 8-year-old children: racial differences and clinical significances. 
In: Hook EB and Porter IH (eds). Population cytogenetic studies in humans. Academic Press, New York, pp 133-159

Madan K, Bobrow M (1974): Structural variation in chromosome No. 9. Ann Genet 17: 81-86

Matsuura J, Mayer M, Jacobs P (1978): A cytogenetic survey of an institution for the mentally retarded. II. C-band chromosome heteromorphisms. Hum Genet 45: 33-41

Mattei MG, Mattei JF, Guichaoua M, Giraud F (1981): Partial inversion of the secondary constriction of chromosome 9. Does it exist? Hum Genet 59: 310-316

Metaxotou C, Kalpini-Mavrou A, Panagou M, Tsenghi C (1978): Polymorphism of chromosome 9 in 600 Greek subjects. Am J Hum Genet 30: 85-89

Muller H, Klinger HP, Glasser M (1975): Chromosome polymorphism in a human new born population. II. Potentials of polymorphic chromosome variants for characterizing the idiogram of an individual. Cytogenet Cell Genet 15: 239-255

Mutton DE, Daker MG (1973): Pericentric inversion of chromosome 9. Nature (New Biol) 241: 80

Shabtai F, Halbrecht I (1979): Risk of malignancy and chromosomal polymorphism: a possible mechanism of association. Clin Genet 15: 73-77

Schweizer D, Ambros P, Andrie M (1978): Modification of DAPI banding on human chromosomes by prestaining with a DNA-banding oligopeptide antibiotic, distamycin A. Exp Cell Res 111: 327-332

Serra A, Bova R, Nei G, Brahe C, Tedesch B (1980): Potential effects of pericentric inversion of the heterochromatic region of chromosome 9 on reproductive fitness. Clin Genet 17:87

Sumner AT (1972): A simple technique demonstrating centromeric heterochromatin. Exp Cell Res 75: 302

Tharapel AT, Summitt RL (1978): Minor chromosome variations and selected heteromorphisms in 200 unclassifiable mentally retarded patients and 200 normal controls. Hum Genet 41: 121130

Tho SPT, Byrd JR, McDonough PG (1982): Chromosome polymorphism in 110 couples with reproductive failure and subsequent pregnancy outcome. Fertil Steril 38: 688-694

Wang HS, Hamerton JL (1979): C-band polymorphisms of chromosomes 1, 9, and 16 in four subgroups of mentally retarded patients and a normal control population. Hum Genet 51 : 269 275

Ward BE, Henry GP, Robinson A (1980): Cytogenetic studies in 100 couples with recurrent spontaneous abortions. Am J Hum Genet 32: 549-554

Willatt L, Davison C, Goudie D, Alexander J, Dyson H, Jenks P (1991): A male with trisomy 9 mosaicism and uniparental chromosome 9 disomy in the euploid cell line. $\mathbf{J}$ Med Genet $\mathbf{2 8}$ : 567-568

Yamada K, Ohta M, Yoshimura K, Hasekura H (1981): A possible association of Y chromosome heteromorphism with stature. Hum Genet 58: 268-270

Yamada K (1985): Relation of stature to length and heterochromatin of the human Y chromosome. In: Sandberg AA (ed). The Y chromosome, Part B: Clinical aspects of $Y$ chromosome abnormalities. Alan R Liss Inc, New York, pp 1-13 